\title{
TFF2/SP-deficient mice show decreased gastric proliferation, increased acid secretion, and increased susceptibility to NSAID injury
}

\author{
James J. Farrell, ${ }^{1}$ Douglas Taupin, ${ }^{2}$ Theodore J. Koh, ${ }^{1}$ Duan Chen, ${ }^{3}$ Chun-Mei Zhao, ${ }^{3}$ \\ Daniel K. Podolsky, ${ }^{1}$ and Timothy C. Wang ${ }^{1}$
}

${ }^{1}$ Massachusetts General Hospital, Gastrointestinal Unit, Boston, Massachusetts, USA
${ }^{2}$ The Canberra Hospital, Gastroenterology Unit, Garran, Australia
${ }^{3}$ University Hospital of Trondheim, Norwegian University of Science and Technology, Trondheim, Norway

Address correspondence to: Timothy C. Wang, University of Massachusetts Medical Center, Division of Gastroenterology, Lazare Research Building, Room 208, 364 Plantation Street, Worcester, Massachusetts 01605-2324, USA.

Phone: (508) 856-4778; Fax: (508) 856-4770; E-mail: Timothy.Wang@umassmed.edu.

Received for publication February 15, 2001, and accepted in revised form December 3, 2001.

Trefoil factor family 2 (TFF2), also known as spasmolytic polypeptide, is a member of the trefoil family of peptides and is expressed primarily in the mucous neck cells of the gastric mucosa. To study the physiologic role of TFF2, we have generated TFF2-deficient mice through targeted gene disruption. Homozygous mutant mice were viable and fertile without obvious gastrointestinal abnormalities. However, quantitative measurements revealed a significant decrease in gastric mucosal thickness and in gastric mucosal proliferation rates. In addition, there was a twofold increase in activated parietal cells resulting in a twofold increase in basal and stimulated gastric acid output and an undetectable serum gastrin level. The TFF2-deficient mice also showed a significant increase in the degree of gastric ulceration after administration of indomethacin. Taken together, these results suggest a physiologic role for TFF 2 to promote mucosal healing through the stimulation of proliferation and downregulation of gastric acid secretion.

J. Clin. Invest. 109:193-204 (2002). DOI:10.1172/JCI200212529.

\section{Introduction}

Trefoil factor 2 (TFF2), also known as spasmolytic polypeptide (SP), is one of three known mammalian trefoil peptides. Trefoil peptides are small $(7-12 \mathrm{kDa})$ protease-resistant proteins secreted by the gastrointestinal mucosa in a lineage-specific manner. The other members of the trefoil family, TFF1 (formerly pS2) and TFF3 (formerly intestinal trefoil factor or ITF), are singledomain trefoil factors that are expressed and secreted predominantly by gastric pit cells $(1-3)$ and intestinal goblet cells, respectively, (4-6). TFF2 is expressed and secreted preferentially by gastric mucous neck cells $(1,2)$.

The critical nature of the role of TFF3/ITF in intestinal homeostasis was only apparent after gene deletion. While the colonic mucosa of unchallenged ITF-deficient mice is normal, damage induced by oral dextran sodium sulphate, which produces a trivial injury in normal mice, could not be repaired (7). The principal defect was an absence of epithelial restitution, the rapid spreading and migration of existing epithelial cells to cover the mucosal breach (8-10). This defect was rescued by topical ITF/TFF3. Indeed both TFF2 and TFF3 have been demonstrated to induce directed cell migration in vitro (11); this action requires serine/threonine phosphorylation and activation of MAP kinases (12). Gene deletion of the mouse gastric foveolar trefoil peptide TFF1/pS2 resulted in gastric hyperproliferation and adenomas (13).

TFF2, the first member of the family to be identified, was isolated by Jorgensen and coworkers from porcine pancreas (called PSP for porcine SP) and found to be present in substantial amounts in porcine exocrine pancreatic secretions (14). In contrast, the human homologue hSP, while found to be $74 \%$ identical to pSP, was expressed predominantly in the stomach with lower levels found in the proximal duodenum and biliary tract but not in the normal human pancreas $(3,15)$. A similar pattern of expression was noted for the rat (2) and murine (3) SP genes. The SP gene was later renamed TFF2, recognizing that the gene product was a member of a larger family of trefoil peptides. Alone among mammalian trefoil peptides, TFF2 comprises two trefoil or P domains; homologous amphibian integumentary proteins contain one to four trefoil domains (16).

While expressed and secreted preferentially by gastric mucous neck cells $(1,2)$, TFF2 is upregulated in diverse pathologic conditions of the gastrointestinal tract. For example, TFF2 gene expression is promptly increased after gut injury, and its expression profile broadens to include the regenerative epithelia of virtually the entire gastrointestinal tract (17-19). Observations by a number of investigators have shown that expression of TFF 2 , as well as other trefoil peptides, is increased at sites of gastric ulceration, duodenal ulceration, and Crohn disease of the small intestine. Increased expression of TFF2 has been observed in patients with peptic ulcer disease secondary to Helicobacter pylori infection, as well as patients with ulcers secondary to nonsteroidal anti-inflammatory drug (NSAID) use (20). After experimentally induced 
gastric ulceration in rats, the increase in TFF2 mRNA expression occurs within minutes (19). In addition, an increase in the number of mucous neck cells expressing TFF2 has been observed in both Helicobacter-infected human patients (21) and Helicobacter-infected mice with both preneoplastic (22) and neoplastic (23) changes of the gastric mucosa. In all of these models, there appears to be a relationship between TFF2/SP gene expression and expansion of the proliferative zone of the mucosa, raising the possibility that TFF2 may be involved in regulating epithelial proliferation in response to injury.

Nevertheless, a precise understanding of the function of TFF 2 has remained elusive. The trefoil peptides are small (7-12 kDa) proteins abundantly expressed and secreted onto the mucosal surface. The first reports on the effects of TFF2 described a possible inhibitory effect on gastric acid secretion (14) and a proliferative effect on several colon cancer cell lines (24). However, these initial observations were made using purified pTFF2 preparations that contained significant contaminants. Studies using purified recombinant TFF2 have tended to support a role in acid inhibition (25). More recently, roles in restitution and the stabilization of the mucin gel layer have been proposed (26). Both these processes may promote gastric cytoprotection and contribute to ulcer healing, and thus rats administered oral and parenteral TFF2 are relatively resistant to gastric erosions induced by indomethacin or alcohol $(27,28)$. These functions may involve the presence of specific receptors for TFF2. However, while several candidate binding proteins have been characterized (29, 30 ), no conclusive TFF2 receptor has been found.

To study further the functional importance of TFF2, we have generated mice deficient in TFF2 through targeted gene disruption. These studies indicate that TFF2 functions to promote gastric mucosal healing through actions that include both inhibition of acid secretion and stimulation of mucosal proliferation.

\section{Methods}

Cloning and sequencing of the mouse TFF2 gene. A Sau3adigested 129/Sv genomic library ligated to the replacement vector LambdaFix II (Strategene, La Jolla, California, USA) was grown and maintained in lysogenic Escherichia coli, XL1-Blue (p2), (Strategene) as described previously (31). Colony lifts were screened by hybridization with $\left[\alpha_{-}{ }^{32} \mathrm{P}\right] \mathrm{dCTP}-\mathrm{labeled}$ probes generated from the rat TFF2 cDNA described (2) or a 50-mer oligonucleotide derived from the $5^{\prime}$ region of the published mouse TFF2 cDNA sequence (1), according to standard screening protocols (25). Three rounds of screening resulted in four individual positive clones that were plaque purified and amplified. From one of these clones, designated mTFF214b, phage DNA was harvested by plate lysis (32) and purified on a cesium chloride gradient, and a $15-\mathrm{kb}$ insert was subcloned into the Not1 site of pBluescript (KS+; Strategene). Restriction endonuclease mapping was performed. Sequencing of both strands was by the dideoxynucleotide method
$(2,3,33)$. The subcloned insert contained four coding exons, $3.5 \mathrm{~kb}$ of $5^{\prime}$ flanking sequence, and $8 \mathrm{~kb}$ of $3^{\prime}$ flanking sequence. The identity of this clone was confirmed by the presence of the TFF 2 cDNA sequence identified previously and by similar restriction patterns of mouse genomic and plasmid DNA.

Mapping of exon-intron borders. Exon-intron borders were assessed by sequencing and confirmed by amplification of introns by PCR using primers derived from intronic and intron-exon spanning sequences. Primers were as follows: intron 1, 5'-CGGGATCCCAGCAGGTGAAAGG-3', $5^{\prime}$-GGGGTACCTGGGAGCTTAGGAC-3';

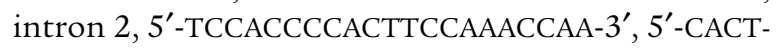
GCTCCGATTCTGGTTT-3' $3^{\prime}$; intron 3, 5' -CTGTGGAAGGTAATGGTTGT-3', 5'-CTTTCTTCTTTCTGGCTTGC-3'. The mTFF2 gene spans 3,114 bases, encompassing four exons and introns of $879 \mathrm{bp}, 772 \mathrm{bp}$, and 1,074 bp (Figure 1a). The sequence was deposited in GenBank (National Center for Biotechnology Information, Bethesda, Maryland, USA; accession number U78770).

Construction of TFF2-targeting vector. The murine TFF2 gene was used to construct a targeting vector by replacing the coding regions (exons 1-4) of the mTFF2 gene with the neomycin resistance gene. This was accomplished by inserting $3.5 \mathrm{~kb}$ of $5^{\prime}$-flanking DNA and $3 \mathrm{~kb}$ of 3 '-flanking DNA into the pPNT vector, which contains a neomycin cassette (neo) as well as the herpes simplex thymidine kinase gene (hsv-tk) (Figure 1b) (33).

Generation of TFF2-deficient mice. The targeting vector was linearized with Pvu1 and electroporated into $\mathrm{J}_{1}$ embryonic stem cells using a Bio-Rad Gene Pulsar apparatus (Bio-Rad Laboratories Inc., Hercules, California, USA) at a capacitance of $500 \mathrm{MF}$ and a voltage of 240 $\mathrm{mV}$. A positive-negative selection strategy (33) was then used to determine which embryonic stem cell clones underwent homologous recombination as opposed to random integration (Figure 1b). Embryonic stem cells were exposed to media containing $200 \mu \mathrm{g} / \mathrm{ml} \mathrm{G} 418$ and $0.2 \mu \mathrm{mol} / 1$ 1-(2'fluoro-2'-deoxy- $\beta$-D-arabinofuranosyl)5 -iodouracil. Two rounds of screening were performed. DNA was isolated from 256 surviving clones and then screened by Southern blot analysis (see below). Two positive clones were identified, expanded, and microinjected into blastocysts from C57BL/6 donors. High-percentage chimeric mice were obtained. The chimeras were bred to $\mathrm{C} 57 \mathrm{BL} / 6$ mice, and the agouti-colored offspring $\left(\mathrm{F}_{0}\right)$ with germline transmission of the targeted mutation were crossed again to $\mathrm{C} 57 \mathrm{BL} / 6$ wild-type mice to generate $F_{1}$ offspring with a mixed genetic background. The $\mathrm{F}_{1}$ mice carrying the germline mutation were back-crossed to each other to generate $\mathrm{F}_{2}$ mice that were knockout (one in four), heterozygous (two in four), and wild-type (one in four). The $\mathrm{F}_{2}$ knockout mice were then bred continuously to establish the knockout line, as verified by Southern blot analysis and PCR (Figure 1, $\mathrm{c}$ and $\mathrm{d}$ ). The $\mathrm{F}_{2}$ wild-type mice were bred to generate the wild-type controls in the same genetic background. Homozygotes were screened for expression of TFF2 by Northern and Western blot analysis. This study was 
$\mathbf{a}$

$|\leftarrow 3.5 \mathrm{~kb} \rightarrow| \leftarrow 3.1 \mathrm{~kb} \rightarrow|\longleftarrow 8 \mathrm{~kb} \longrightarrow|$

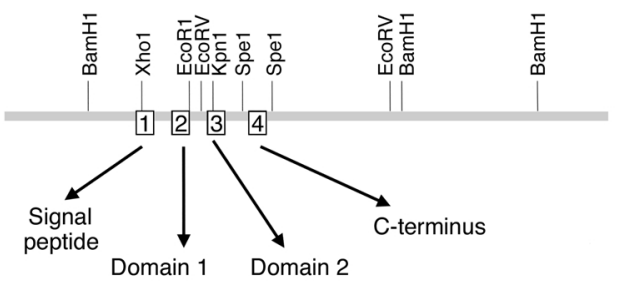

C
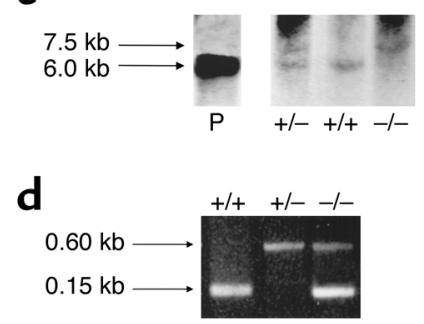

b
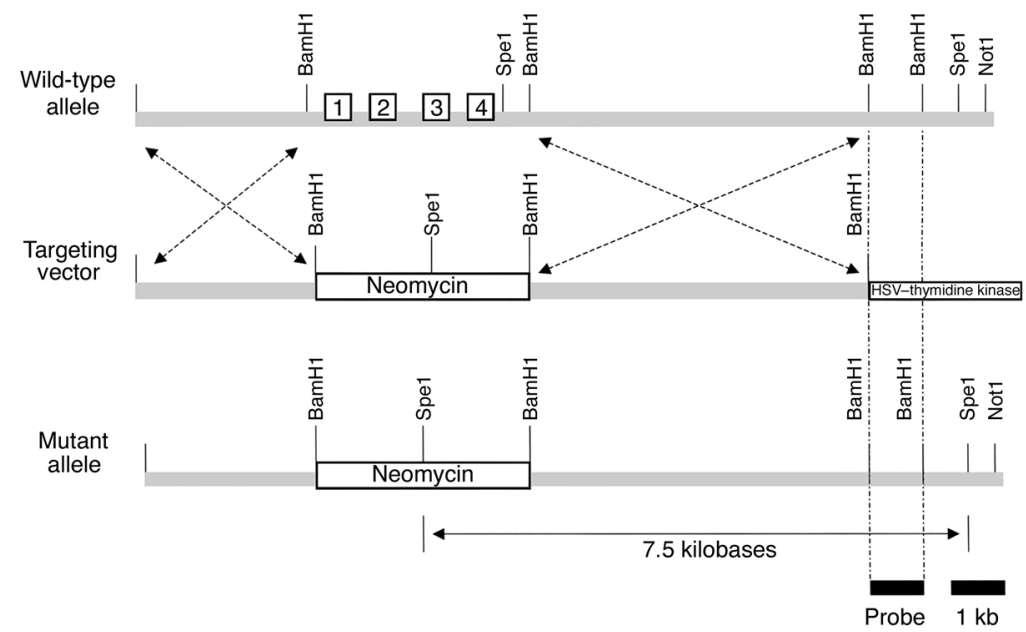

Figure 1

Targeted deletion of the mouse TFF2 gene. (a) Restriction map of the 15-kb genomic clone mTFF2. The subcloned gene contained four coding exons, $3.5 \mathrm{~kb}$ of $5^{\prime}$ flanking sequence and $8 \mathrm{~kb}$ of $3^{\prime}$ flanking sequence. The mTFF2 gene spans 3,114 bases, encompassing four exons (depicted in numbered boxes) that span a total of $3.7 \mathrm{~kb}$ and introns of $879 \mathrm{bp}, 772 \mathrm{bp}$, and 1,074 bp. Exon 1: bp 439 to 516 ; exon 2: bp 1,396 to 1,545; exon 3: bp 2,318 to 2,464; exon 4: bp 3,539 to 3,553. The peptide domains encoded are indicated by arrows. (b) Strategy for homologous recombination. A diagram of the TFF2-pPNT targeting vector (middle) designed to replace the BamH1-BamH1 fragment containing the TFF2 exons in the wild-type (top) with a PGK-neo cassette and a herpes simplex virus-thymidine kinase (HSV-thymidine kinase) cassette. The predicted mutant allele (bottom) generated by homologous recombination is also shown. The neomycin resistance gene (Neomycin) is retained in the mutant allele with homologous recombination, while the HSV-thymidine kinase is not. (c) Southern blot analysis of the homologous recombination. Southern blot analysis of wild-type (+/+), heterozygous (+/-), and TFF2-deficient (-/-) mice shows that the 6-kb Spe1 restriction fragment found in wild-type mice is lost in TFF2-deficient mice because of the deletion of a single Spe 1 site just distal to exon 4, resulting in a 7.5-kb fragment. The 15-kb mTFF2 genomic clone in pBKS+ was used as a positive control (P). (d) Polymerase chain reaction analysis of tail DNA using the neomycin resistance gene and mouse TFF2 exon 2 primers reveals a solitary $0.6-k b$ fragment representing heterozygosity $(+/-)$ and a solitary $0.15-\mathrm{kb}$ fragment representing wild-type $(+/+)$.

approved by the Massachusetts General Hospital Subcommittee on Research Animal Care (SRAC).

Genomic Southern blot analysis. Embryonic stem (ES) cell or tail genomic DNA $(15 \mu \mathrm{g})$ was extracted by proteinase $\mathrm{K}$ digestion, phenol/chloroform extraction, and ethanol precipitation, and digested with Spe1 restriction enzyme. After gel electrophoresis (0.8\% agarose) in 40 $\mathrm{mM}$ tris-acetate- $1 \mathrm{mM}$ EDTA buffer and alkaline transfer to nylon, blots were hybridized to a $[\alpha-32 \mathrm{P}] \mathrm{dCTP}-$ labeled probe generated from a 1-kb BamH1 TFF2 fragment $3^{\prime}$ to the flanking sequence present in the targeting vector. The Southern blot strategy takes advantage of the change in location of the Spe1 site by the neo cassette in the setting of homologous recombination. Homologous recombination thus results in an increase in the Spe1 restriction fragment size from $6 \mathrm{~kb}$ to $7.5 \mathrm{~kb}$ (Figure $1 \mathrm{c}$ ). PCR screening strategy. PCR from tail DNA was performed using $100 \mathrm{ng}$ template DNA and $20 \mathrm{pmol}$ of each primer in a volume of $20 \mu \mathrm{l}$ containing $\mathrm{MgCl}_{2}(1.5 \mathrm{mM})$ and $1 \mathrm{U}$ Taq polymerase (Perkin-Elmer Life Sciences Inc., Boston, Massachusetts, USA). For combined exon 2 of mTFF2 gene and neomycin resistance gene amplification, a first denaturation step was performed at $94^{\circ} \mathrm{C}$ for 8 minutes. Thirty cycles $\left(20\right.$ seconds at $94^{\circ} \mathrm{C}, 60$ seconds at $64^{\circ} \mathrm{C}$, and 60 seconds at $72^{\circ} \mathrm{C}$ ) were performed in an automated thermocycler (Perkin-Elmer Life Sciences Inc.). An extension step at $72^{\circ} \mathrm{C}$ for 8 minutes was also performed. The following DNA primers were used: exon 2, mTFF2 (downstream), 5' ATGATGGCTCGCTCTATCCACA; mTFF2 (upstream), 5’ TAAGCCGACAGCTGGCAGAA; neomycin resistance gene (downstream), 5' CGGCTGCTCTGATGCCGCC; neomycin resistance gene (upstream), 5'GCCGGCCACAGTCGATGAATCC. PCR amplification of both neomycin and mTFF2 gene fragments from mouse tail DNA identified both heterozygous and homozygous knockout mice (Figure 1d).

Northern blot analysis. RNA was prepared from homogenized tissue extracts from 6-week-old mice using TRIzol method (Invitrogen, Carlsbad, California, USA), and RNA blots were performed as previously described (34). Blots were hybridized with an $\left[\alpha^{32} \mathrm{P}\right]$ dCTPlabeled mouse TFF2 exon 2 random-primed, 0.15-kb probe (Figure 2a, top) and mouse TFF1 cDNA randomprimed probe (Figure $2 \mathrm{~b}$ ). The mTFF1 was a generous gift of James Goldenring (Medical College of Georgia, Augusta, Georgia, USA). The mTFF1 probed blot was stripped and reprobed with a GAPDH cDNA randomprimed probe. Probes were labeled using the 


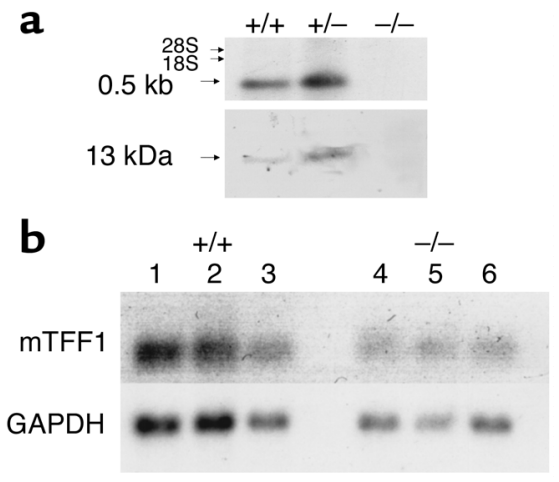

\begin{abstract}
Figure 2
Absence of expression of TFF2 mRNA and peptide in TFF2-deficient mice. (a) Northern blot analysis of stomach RNA (top; $20 \mu \mathrm{g}$ RNA per lane) using a mouse TFF2 exon 2 probe. TFF2-deficient mice (-/-) have no expression ofTFF 2 mRNA compared with heterozygous mice $(+/-)$ or wild-type mice $(+/+)$. Western blot analysis of stomach protein (bottom; $50 \mu \mathrm{g}$ total protein per lane) using an $\mathrm{Ab}$ to human TFF2. TFF2-deficient mice have no expression of TFF2 protein compared with heterozygous mice or wild-type mice. Purified human TFF2 was used as a positive control (not shown). (b) Northern blot analysis of stomach RNA ( $20 \mu \mathrm{g}$ RNA per lane) using a mouse TFF1 probe. Northern blot analysis was performed on gastrin deficient (-/-) and wild-type mice $(+/+)$ as described in Methods. Twenty micrograms of RNA was loaded per lane. The blot was probed with an mTFF1 cDNA probe. The blot was then stripped and reprobed with a GAPDH cDNA probe. The TFF2-deficient mice (-/-) (lanes 4-6) have no increased expression ofTFF1 mRNA compared with wild-type mice $(+/+)$ (lanes 1-3) when controlled for GAPDH expression.
\end{abstract}

Megaprime labeling kit (Amersham Life Sciences Inc., Arlington Heights, Illinois, USA).

Western blot analysis. The entire mouse stomach (including fundus, body, and antrum) was homogenized (Kinematica AG, Littau-Lucerne, Switzerland) in lysis buffer containing $1 \mathrm{M}$ HEPES ( $\mathrm{pH}$ 7.4), $1 \mathrm{mg} / \mathrm{ml}$ aprotonin, 1 $\mathrm{mg} / \mathrm{ml}$ leupeptin, $0.1 \mathrm{M}$ sodium orthovnadate, $0.1 \mathrm{M}$ sodium fluoride, $0.1 \mathrm{M}$ sodium pyro-phospate, $0.5 \mathrm{M}$ EDTA, and $1 \mathrm{M} \mathrm{MgCl}_{2}$. Homogenates were cleared by centrifugation at $13 \mathrm{~g}$ for 10 minutes at $4{ }^{\circ} \mathrm{C}$, suspended in SDS tricine sample buffer, denatured by boiling, and separated by SDS/PAGE (10-20\% SDS tricine gel) before transfer to PVDF membranes. Membranes were blocked in $5 \%$ nonfat powdered milk in Tris buffer $(10 \mathrm{mmol} / \mathrm{l}$ Tris $\mathrm{HCl}, \mathrm{pH} 7.5,100 \mathrm{mmol} / \mathrm{l} \mathrm{NaCl}, 0.05 \%$ Tween 20 ) before incubation with either rabbit $\mathrm{mAb}$ against human TFF2 or goat $\mathrm{mAb}$ against human heparin-binding epidermal growth factor (HB-EGF). TTF2 and HB-EGF proteins were detected by an enhanced chemiluminescence method according to the manufacturer's directions, using a 1:1,000 dilution of primary $\mathrm{Ab}$ and 1:10,000 of the secondary Ab (New England Nuclear Life Science Products Inc., Boston, Massachusetts, USA). Western blotting for the TTF2 was performed using the rabbit antiserum against human TFF2 (Convance Inc., Princeton, New Jersey, USA). The rabbit $\mathrm{mAb}$ against human TFF2 was made using the whole recombinant peptide produced in a yeast expression vector donated previous- ly by Lars Thim (Novo Nordisk A/S, Malov, Denmark) (35). The Ab against human TFF2 has been shown to be specific for mouse and rat TFF2 (2). The membranes were washed and incubated with anti-rabbit IgG horseradish peroxidase (HRP) (Amersham Life Sciences Inc.) and the signal was visualized by chemiluminescence (Figure 2a, bottom). The anti-HB-EGF (M-18) Ab and the corresponding secondary Ab (anti-goat IgG-HRP, preabsorbed) were purchased from Santa Cruz Biotechnology (Santa Cruz, California, USA) (see Figure 4d) (23).

Histological evaluation. Gastric tissue from four TTF2deficient and four wild-type mice of equivalent age (8 weeks) and genetic background was used for the purpose of histological comparison. The stomachs were randomly coded, and both macroscopic and microscopic assessment were performed in a blinded fashion. The tissue examined consisted of a section of gastric mucosa taken from the greater curvature of the stomach beginning at the gastroesophageal junction and ending at the gastroduodenal junction. Gastric tissues were fixed in neutral buffered $10 \%$ formalin, processed by standard methods, embedded in paraffin, sectioned at $5 \mu \mathrm{m}$, and stained with hematoxylin and eosin (H\&E) (Figure 3, a and b). Quantitation of total cells and cell subtypes per gastric gland. Gastric total or parietal cells were quantitated with a micrometer eyepiece (OCM $10 \times 10$ SG; Olympus Optical Co., Tokyo, Japan) on H\&E-stained sections from the mouse stomachs. A total of ten randomly selected well-orientated glands in the midbody were chosen per section and examined for total and parietal cells. Results were expressed as mean number of total or parietal cells per gland. Gastric chief cells and mucous neck cells were quantitated and expressed similarly (cells per gland), except on toluidine blue-stained sections from the mouse stomachs (36) (Figure 3, c and d). The chief cells are characterized by dark blue, supranuclear secretory granules and by a uniform basophilia below and beside the nucleus. Mucous neck cells were identified as small triangular cells in the neck region of the gland, with associated granules at the surface. We could not use the standard marker for mucous neck cells (TFF2). Endocrine cells were stained specifically with anti-chromogranin A Ab as described previously (35). Immunohistochemistry was performed with avidin-biotin-peroxidase complex $(\mathrm{ABC})$ method by commercial $\mathrm{ABC}$ kits (Vector Laboratories, Burlingame, California, USA). Polyclonal anti-porcine chromogranin A (DiaSorin Inc., Stillwater, Minnesota, USA) was used as a marker of endocrine cells at a final dilution of 1:500. Endocrine cells were quantitated in both TFF2-deficient and wildtype gastric corpus sections and expressed as number of positive-staining cells per millimeter of horizontal length of gastric corpus mucosa (Figure 3, e and f).

Calculation of mucosal thickness, pit region, and gland height. To calculate mucosal thickness, ten well-orientated oxyntic gastric glands, whose lumens could be seen throughout their entire length, were counted per section and measured with an Olympus FW $\times 10$ micrometer eyepiece along its perpendicular axis (Olympus America 
Inc., Melville, New York, USA). Results are expressed as the mean mucosal thickness (in micrometers).

The gastric unit is comprised of four zones: (a) the pit region containing surface mucous cells, (b) the isthmus containing multipotent gastric stem cells, (c) the neck containing mucous neck cells, and (d) the basal region containing chief cell and enteroneuroendocrine cells. The region containing the isthmus, neck, and basal region is commonly known as the "gland." Both glandular and pit heights were measured in 20 well-orientated oxyntic glands, using an Olympus FW $\times 10$ micrometer eyepiece, along their perpendicular axis (Olympus America Inc.). Results are expressed as the mean size of each region (in micrometers).

5-bromo-2'-deoxyuridine immunobistochemistry. Four TTF2-deficient and four wild-type mice (8 weeks old) were injected with $50 \mathrm{mg} / \mathrm{kg} 5$-bromo-2'-deoxyuridine $(\mathrm{BrdU})$ intraperitoneally using freshly prepared stock solution $(5 \mathrm{mg} / \mathrm{ml})$ dissolved in PBS. The mice were killed 1 hour later, and tissue samples were placed in a cassette overnight, fixed in Carnoy's solution, and paraffin-embedded. Immunohistochemical detection of BrdU incorporation was performed using the avidinbiotin $\mathrm{mAb}$ technique as described previously (36). Ten well-oriented oxyntic glands were counted per mouse. The BrdU labeling index was calculated by counting the number of BrdU-positive cells per gland.

Electron microscopy. Four TTF2-deficient mice and four wild-type mice ( 8 weeks) were killed by $\mathrm{CO}_{2}$ asphyxiation, and their stomachs fixed in situ by ligation of the esophagus and pylorus followed by injection of fixative (2.5\% paraformaldehyde, $5 \%$ glutaraldehyde, and $0.01 \%$ picric acid in $0.1 \mathrm{~mol} / 1$ sodium cacodylate buffer, $\mathrm{pH} 7.4$ ) into the lumen. After 2 hours at room temperature, tissue from the oxyntic gland area was washed in $0.1 \mathrm{~mol} / 1$ sodium cacodylate, $\mathrm{pH} 7.4$, post-fixed in $1 \%$ osmium tetroxide in $0.1 \mathrm{~mol} / 1$ sodium cacodylate buffer, $\mathrm{pH} 7.4$, treated with uranyl acetate in maleate buffer, and then washed in the same buffer $(22,34)$. Specimens were dehydrated in cold, graded ethanol series and, after propylene oxide treatment, embedded in a mixture of Epon Araldite (Electron Microscopy Science, Fort Washington, Pennsylvania, USA). The mucosa was sectioned with the base-to-pit axis of gastric glands parallel to the cutting surface. Semithin sections ( $5 \mu \mathrm{m}$ thick) were stained with $1 \%$ toluidine blue in $1 \%$ sodium borate for light microscopy. Photographs were taken with a Zeiss Axiophot microscope. Adjacent thin sections, 0.08-0.1 $\mathrm{mm}$ thick, were stained with uranyl acetate and lead citrate and examined with a JEOL 1200 EX electron microscope (JEOL Ltd., Tokyo, Japan). The cells were photographed (nucleated profiles only) at $\times 3,000$.

Measurement of basal gastric acid output. All acid studies were performed in a blind fashion with the genotype of the gastric sample unknown to the investigator at the time of analysis. Gastric $\mathrm{pH}$ was measured using a modification of the method of Langhans et al. (36). Eight wild-type and eight TFF2-deficient mice of equivalent age ( $\sim 8$ weeks old) were allowed access to food and water. Mice were anesthetized with $2 \%$ tribromoethanol (Avertin) given by intraperitoneal injection. An incision was made through the abdominal cavity, and the duodenum was ligated just distal to the pyloric outlet. Gastric contents were removed through an incision at the gastroesophageal junction immediately after pyloric ligation. The liquid component of the gastric content was then collected after centrifugation at $9.3 \mathrm{~g}$ for 5 minutes. The volume was calculated. The acidity of the gastric contents was measured by titration with $0.01 \mathrm{~N} \mathrm{NaOH}$ and expressed as microequivalents of $\mathrm{H}^{+}$.

Measurement of stimulated gastric acid output. All stimulated gastric acid studies were performed in a blind fashion with the genotype of the gastric sample unknown to the investigator at the time of analysis. Gastric $\mathrm{pH}$ was
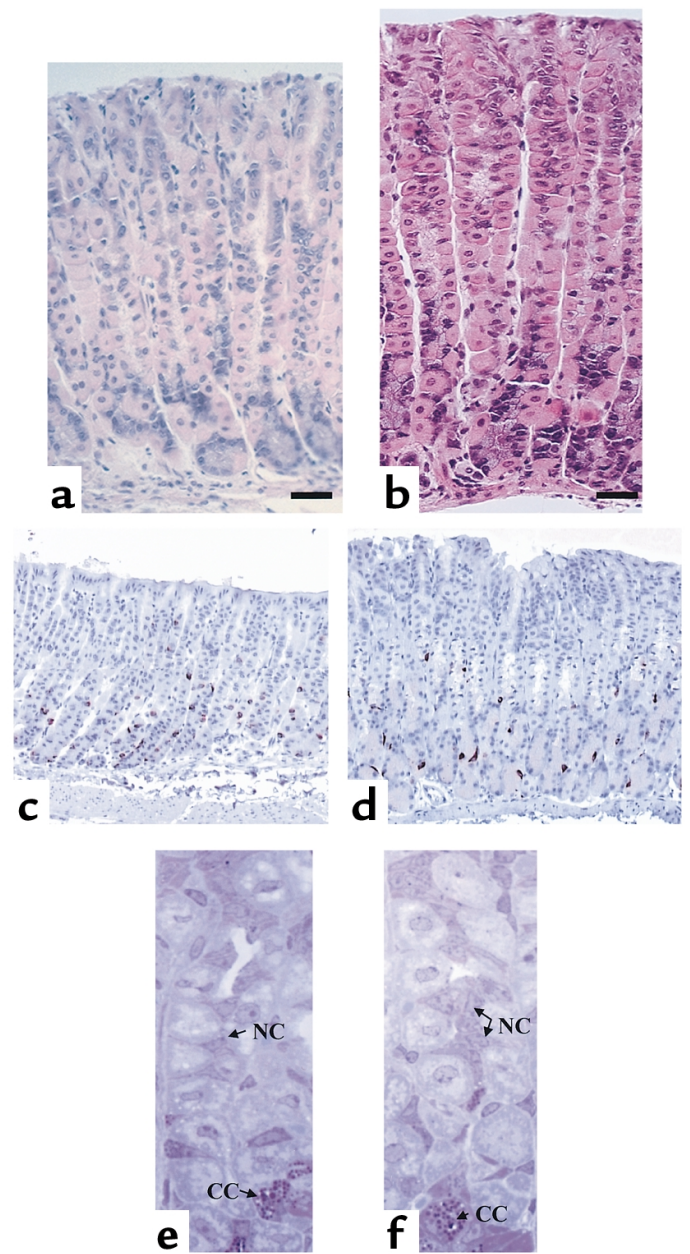

\section{Figure 3}

Histological analysis of TFF2-deficient mice. Representative histological section of mouse gastric body mucosa in TFF2-deficient mice (a) and wild-type mice (b) showing decreased mucosal thickness in the TFF2-deficient mice (H\&E: $\times 40$; bar, $0.05 \mathrm{~mm}$ ). Immunohistochemical micrographs of mouse oxyntic mucosa (transverse section) showing chromogranin A-positive cells in TFF2-deficient mice (c) and wild-type mice $(\mathbf{d})(\times 40)$. For the staining method and cell density, see text. Toluidine blue stain of mouse gastric body mucosa, showing decreased mucous neck cells (NC) in TFF2-deficient mice (e) compared with wild-type mice $(\mathbf{f})$. Chief cells are also shown (CC). Toluidine blue $\times 80$. 
measured using a modification of the method of Langhans et al. (37). Eight wild-type and eight TFF2-deficient mice of equivalent age ( $\sim 8$ weeks old) were allowed access to water and were administered bethanechol (2.5 $\mathrm{mg} / \mathrm{kg}$ intraperitoneally) 1 hour before sacrifice. Mice were anesthetized with $2 \%$ tribromoethanol (Avertin) given by intraperitoneal injection. An incision was made through the abdominal cavity, and the duodenum was ligated just distal to the pyloric outlet. Gastric contents were removed through an incision at the gastroesophageal junction immediately after pyloric ligation. The liquid component of the gastric content was then collected after centrifugation at $9.3 \mathrm{~g}$ for 5 minutes. The volume was calculated. The acidity of the gastric contents was measured by titration with $0.01 \mathrm{~N} \mathrm{NaOH}$ and expressed as microequivalents of $\mathrm{H}^{+}$.

Quantitation of parietal cell activation. Random low-powered electron micrographs were obtained $(3,000 \times)$. Both activated and inactivated parietal cells were identified by their unique ultrastructure. Activated parietal cells were defined as cells having secretory canaliculi. Over 500 parietal cells were counted in four wild-type and four TTF2-deficient mice. The results are reported as the number of activated parietal cells expressed as a percentage of total parietal cell number. Activated parietal cell count was determined in the unstimulated fed state (basal acid secretion).

Assay for serum gastrin peptides and TGF- $\alpha$. Serum was obtained by tail bleeding from four TFF2-deficient and four wild-type mice for assay of circulating gastrin. Gastrin concentrations were determined by radioimmunoassay using Ab's to the $\mathrm{COOH}$ terminus of gastrin, as described previously (38). TGF- $\alpha$ present in gastric tissue was also measured by radioimmunoassay (RIA) as reported previously (23).

NSAID gastric injury model. Sixteen TFF2-deficient mice and 16 wild-type mice (19-26 g weight and 8 weeks old) were randomized to receive indomethacin. Indomethacin (Sigma Chemical Co., St. Louis, Missouri, USA) (20-40 $\mathrm{mg} / \mathrm{kg}$ in $5 \%$ sodium bicarbonate) was administered intraperitoneally $12-24$ hours before sacrifice. One hour before sacrifice all animals were given bethanechol (2.5 $\mathrm{mg} / \mathrm{kg}$ intraperitoneally) to increase gastric acid secretion, which makes existing lesions more discernible macroscopically. After sacrifice, stomachs were dissected open along the lesser curve. The fundus was removed, and the remaining stomach was flattened by pinning. After fixing in 10\% neutral buffered formalin overnight, the stomachs were divided horizontally into six sections of equal thickness and processed for histology as above.

Histological assessment was performed by one investigator blinded to the genotype and treatment (indomethacin dose and time) of the mice. Ulcers were defined as damage to the epithelial surface ranging from epithelial disruption to deep ulceration to the lamina propria in association with an inflammatory infiltrate. The initial assessment involved counting the number of ulcers per horizontal stomach section (six transverse sections per stomach). This means of assess- ment took both the size (length of ulcers) and number of ulcers into account and was validated previously by showing a dose response at lower doses of indomethacin $(5,10,15$, and $20 \mathrm{mg} / \mathrm{kg}$ indomethacin). This method of ulcer quantitation is more objective than planimetry and more suited to the assessment of NSAID-induced ulcers in mice, which are linear.

Ulcer histological scoring. Histological evaluation of the severity of ulceration and the degree of associated inflammation was performed by an investigator blinded to the group and treatment of the animals, using a validated scoring system described previously (39). The damage score was assigned based on the following scale: 0 = normal; 1 = edema and/or vacuolation, but minimal changes in crypt architecture; 2 = epithelial disruption; 3 = erosion extending to the muscularis mucosae. The inflammatory scoring system was established after review of all slides to assess the range of inflammation, and the following scores were then assigned as follows: $0=$ normal $; 1=$ minimal inflammatory cells; $2=$ mod erate number of inflammatory cells; 3 = large number of inflammatory cells. Ulcer damage and inflammation scores were calculated after administration of indomethacin $(20 \mathrm{mg} / \mathrm{kg})$ for 12 and 24 hours. Over 60 ulcers were assessed in both wild-type and TFF2-deficient mice at each time point. Results are expressed as the mean damage and inflammation score ( \pm SEM).

Statistical analysis. The results are expressed as means plus or minus SEM, unless otherwise stated. The statistical significance of difference was evaluated with the Student $t$ test. A $P$ value of less than 0.05 was considered statistically significant.

\section{Results}

Cloning and sequencing of murine TFF2. The complete murine TFF2/SP gene was cloned and sequenced (see Methods). Three rounds of screening of a mouse $129 / \mathrm{Sv}$ genomic library with a rat TFF2 cDNA probe followed by plaque purification resulted in isolation of four individual positive clones. One of these clones was then subcloned into the Not1 site of pBluescript KS+. The subcloned inset contained four coding exons, 3.5 $\mathrm{kb}$ of $5^{\prime}$ flanking sequence, and $8 \mathrm{~kb}$ of $3^{\prime}$ flanking sequence. Restriction mapping was performed and showed similar restriction patterns of mouse genomic and plasmid DNA.

The gene (Figure 1a) spanned 3,114 bases, encompassing four exons and introns of $879 \mathrm{bp}, 772 \mathrm{bp}$, and 1,074 bp. These introns were confirmed by PCR amplification based on exon-intron junction spanning primers. The sites of exon 1 were bp 439-516; exon 2 bp 1,396-1,545; exon 3 bp 2,318-2,464; and exon 4 bp 3,539-3,553.

The nucleotide sequence of the open reading frame is identical to that derived from the published mouse TFF2 cDNA sequence (3). The first exon encodes the putative signal peptide and the three $\mathrm{N}$-terminal amino acids, Glu, Lys, and Arg. Exons 2 and 3 encode the first and second trefoil domain, respectively. Exon 4 encodes the C-terminal four amino acids and 3 ' untranslated 
region. When corresponding cysteine residues of the trefoil domains are aligned, exons 2 and 3 share $51 \%$ identity at the nucleotide level and $41 \%$ at the amino acid level. The regions around the second and sixth paired cysteine residues are most homologous, suggesting that the conserved residues are required to bring these cysteines in proximity to the fourth and third cysteines, respectively, and allow formation of the trefoil loop. The amino acid homology between the individual trefoil domains $(41 \%)$ is comparable to those seen between single domain trefoil peptides within species (mouse TFF1 vs. mouse TFF3, 35\%; human TFF1 vs. human TFF3, $36 \%$ ) (40). In contrast, mouse, rat, and human SP peptide sequences approach $90 \%$ identity. This argues in favor of SP having an evolutionary origin as a duplication of separately encoded single peptide domains. In addition, the murine TFF2 gene structure is similar to that described for human TFF2.

Absence of TFF2 $m R N A$ and protein expression in mice homozygous for the disrupted $m$ TFF2 allele. Mice with a disrupted TFF2 gene were generated by targeted gene disruption in murine $\mathrm{J}_{1}$ ES cells (Figure 1b). Two independent ES clones were generated and used successfully to establish germline chimeras and their heterozygous mutant offspring. Heterozygous $\left(\mathrm{TFF}^{+/-}\right)$matings resulted in litters with the expected Mendelian frequency of wild-type pups, heterozygote pups, and homozygous (TFF2-/-) TFF2-deficient pups. Thus, targeted disruption of the SP did not affect viability during embryogenesis. TFF2-deficient mice were normal in size, were fertile, and had normal litter size compared with their heterozygous and wild-type litter mates.

Southern blot analysis and PCR analysis of genomic DNA isolated from the tails of targeted mice confirmed that the TFF2 gene had been correctly deleted (Figure 1, $c$ and d). Spe1 digestion of genomic DNA resulted in generation of a $7.5-\mathrm{kb}$ fragment unique to the homologous recombinant and/or a $6.0-\mathrm{kb}$ fragment unique to the wild-type allele. The 1-kb DNA probe was common to both fragments. Hence Southern blot analysis revealed a solitary $6-\mathrm{kb}$ fragment compatible with the wild-type allele, a $7.5-\mathrm{kb}$ fragment compatible with homozygous TFF 2 gene deletion, and both a $6-\mathrm{kb}$ and 7.5 -kb fragment seen with heterozygous gene deletion. The cloned mTFF2 plasmid gene was used as a positive control (Figure 1c). Similarly, PCR using primers for both the presence of mTFF2 exon 2 and the neomycin resistance gene demonstrated a solitary 0.15$\mathrm{kb}$ fragment consistent with the wild-type allele (only exon 2), a single $0.6-\mathrm{kb}$ fragment indicative of the neomycin resistance gene (hence homozygous gene deletion of the TFF2 gene), and both a $0.15-\mathrm{kb}$ and $0.6-\mathrm{kb}$ fragment with heterozygous gene deletion (Figure 1d).

The absence of TFF2 expression was confirmed by Northern blot analysis using a murine TFF 2 exon 2 probe and by Western blot analysis using a rabbit anti-human TFF2

Table 1
$\mathrm{Ab}$ (Figure 2a). Thus, mice homozygous for the disrupted TFF2 gene were unable to transcribe TFF2 mRNA (Figure 2a, top) or generate TFF2 protein (Figure 2a, bottom). There was no evidence of increased TFF1 mRNA expression in TFF2-deficient mice compared with wild-type mice (Figure 2c).

TFF2 deficiency results in decreased proliferation of the gastric mucosa, with decreased mucosal thickness, pit size, and gland beight, but normal glandular parietal cell count. Analysis of TFF2-deficient mice by routine histology showed a significant $(-11.5 \%)$ decrease in the thickness of the oxyntic mucosa $(0.603 \pm 0.0125 \mathrm{~mm}$ vs. $0.682 \pm 0.0189 \mathrm{~mm}$ ) (Figure 3 , a and $b)$ and total glandular cell count $(70 \pm 1.5$ vs. $86 \pm 1.7$ cells per gland, $P<0.05$ ) (Table 1$)$. There was not a statistically significant difference in total parietal cell count or total chief cell count, although the total endocrine cell count per gland was increased in TFF2deficient mice $(56.5 \pm 2.4$ cells per millimeter horizontal length of mucosa vs. $42.6 \pm 2.9$ cells per millimeter horizontal length per millimeter, $P<0.05$ ) (Figure 3 , $c$ and d). Furthermore, there was a statistically significant decrease in the numbers of mucous neck cells (Figure 3 , e and $f$ ) per gland in TTF2-deficient mice compared with wildtype mice $(6.54 \pm 0.38$ cells per gland vs. $9.2 \pm 0.59$ cells per gland, $P<0.004)$ (Table 1$)$.

The gastric unit is comprised of four zones: (a) the pit region containing surface mucous cells, (b) the isthmus containing multipotent gastric stem cells, (c) the neck containing mucous neck cells, and (d) the basal region containing chief cells and enteroendocrine cells. The region containing the isthmus, neck, and basal region is commonly known as the "gland". Both the pit region size $(0.159 \pm 0.0048 \mathrm{~mm}$ vs. $0.189 \pm 0.0123 \mathrm{~mm}$, $P<0.05)$ and the glandular height $(0.444 \pm 0.0024 \mathrm{~mm}$ vs $0.493 \pm 0.0033 \mathrm{~mm}, P<0.05)$ were significantly smaller in the TFF2-deficient mice compared with the wild-type mice (Table 1).

To determine if the decrease in mucosal thickness, pit region, and glandular height was related to changes in epithelial proliferation, BrdU incorporation was assessed in mice fed ad libitum. Interestingly, there was a significant decrease in the rate of proliferation of the gastric mucosa in the TFF2-deficient mice compared

Effect of TFF2 deficiency on gastric mucosal thickness

\begin{tabular}{lcc} 
& TFF2-deficient mice & Wild-type mice \\
Gastric mucosal thickness & $0.603 \pm 0.0125 \mathrm{~mm}^{\mathrm{B}}$ & $0.682 \pm 0.0189 \mathrm{~mm}$ \\
Total cells per gland & $70.0 \pm 1.5^{\mathrm{B}}$ & $86.3 \pm 1.7$ \\
Parietal cells per gland & $15.2 \pm 0.62$ & $14.18 \pm 0.11$ \\
Chief cells per gland & $8.44 \pm 0.32$ & $8.9 \pm 0.33$ \\
Endocrine cells (cells/mm) ${ }^{\mathrm{A}}$ & $56.5 \pm 2.4^{\mathrm{C}}$ & $42.6 \pm 2.9$ \\
Mucous neck cells per gland & $6.45 \pm 0.38^{\mathrm{C}}$ & $9.2 \pm 0.59$ \\
Gastric pit region & $0.159 \pm 0.0048 \mathrm{~mm}^{\mathrm{C}}$ & $0.189 \pm 0.0123 \mathrm{~mm}$ \\
Gastric glandular height & $0.444 \pm 0.0024 \mathrm{~mm}^{\mathrm{C}}$ & $0.493 \pm 0.0033 \mathrm{~mm}$ \\
Proliferation rate (LI) & $1.86 \pm 0.17^{\mathrm{D}}$ & $2.8 \pm 0.25$ \\
\hline
\end{tabular}

$\mathrm{LI}$, labeling index (number of BrdU-positive cells per gland). ${ }^{A}$ Endocrine cells measured as cell number per millimeter of horizontal length of mucosa; ${ }^{\mathrm{B}} P<0.0005 ;{ }^{\mathrm{C}} P<0.05$; $\mathrm{D} P<0.004$. 

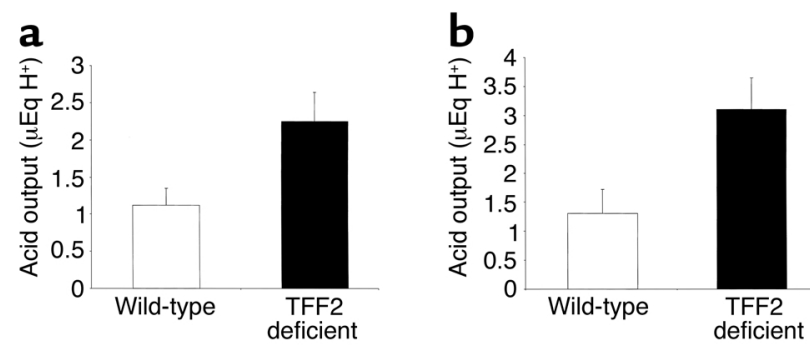

c
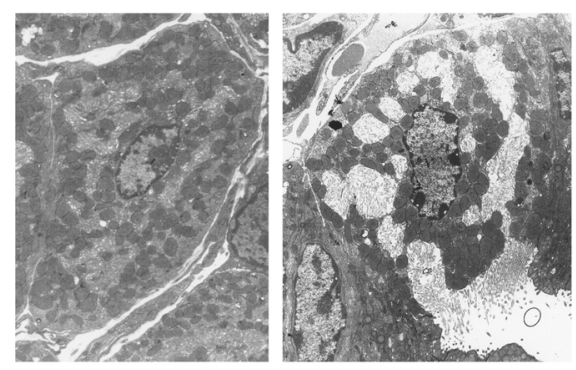

d

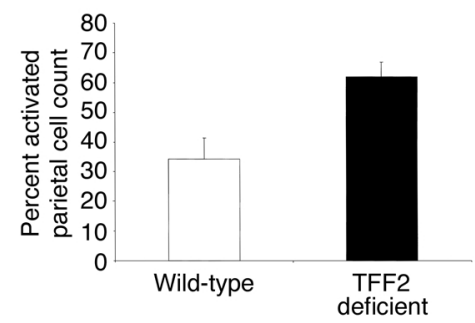

e

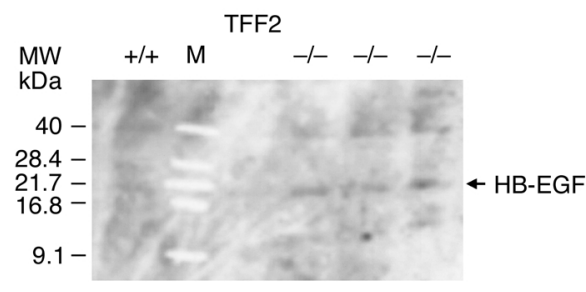

with control mice (Table 1). The TFF2-deficient mice showed a BrdU-labeling index of $1.86 \pm 0.17$ compared with wild-type mice, which showed a BrdU-labeling index of $2.8 \pm 0.25(P<0.004)$, which represented a $33.6 \%$ decrease in proliferation.

Increased acid secretion in TFF2-deficient mice associated with increased parietal cell activation. TFF2-deficient mice showed a nearly twofold increase in gastric acid output under unstimulated fed $\left(2.06 \pm 0.39 \mu \mathrm{Eq} \mathrm{H^{+ }}\right.$ vs. $1.12 \pm 0.23 \mu \mathrm{Eq} \mathrm{H} \mathrm{H}^{+}, P<0.05$ ) (Figure $4 \mathrm{a}$ ) and bethanechol-stimulated $\left(3.11 \pm 0.54 \mu \mathrm{Eq} \mathrm{H} \mathrm{H}^{+}\right.$vs. $1.31 \pm 0.41 \mu \mathrm{Eq}$ $\mathrm{H}^{+}, P<0.04$ ) (Figure $4 \mathrm{~b}$ ) conditions compared with wildtype mice. This increase in acid secretion correlated with an increase in parietal cell activation in TFF2-deficient mice as measured by transmission electron microscopy (see Methods). Parietal cell activation is easily identified based on fusion of tubulovesicles and/or expansion of secretory canaliculi (Figure 4c). Thirty-four percent of parietal cells were activated in the resting state, which was roughly similar to percentages for wild-type mice published previously (34). In contrast, over $62 \%$ of parietal cells were found to be activated under nonstressed fed conditions in TFF2-deficient mice (Figure 4d), a dif-

\section{Figure 4}

Increased parietal cell activation and acid secretion in TFF2-deficient mice. (a) Increased basal gastric acid secretion in fed TFF2-deficient mice. Basal gastric acid output was calculated in the resting state of fed wild-type and TFF2-deficient mice and expressed as $\mu$ Equivalent of $\mathrm{H}^{+}$. Results are expressed as mean acid output \pm SEM and represent data from analysis of eight wild-type mice and eight TFF2-deficient mice. $(P<0.05)$. (b) Increased stimulated gastric acid secretion in TFF2-deficient mice. Stimulated gastric acid output was calculated in wild-type and TFF2-deficient mice after administration of bethanechol ( $2.5 \mathrm{mg} / \mathrm{kg}$ intraperitoneally) and expressed as $\mu$ Equivalent of $\mathrm{H}^{+}$. Results are expressed as mean acid output \pm SEM and represent data from analysis of eight wild-type mice and eight TFF2-deficient mice. $(P<0.04)$. (c) Parietal cell activation. Random low-powered electron micrographs were obtained $(\times 3,000)$. Both activated and inactivated parietal cells are identified by their unique ultrastructure. Activated parietal cells are defined as cells having an expansion of their secretory canaliculi. Inactive parietal cell (left panel). Activated parietal cell (right panel). (d) Increased parietal cell activation in fed TFF2-deficient mice compared with wild-type mice under resting conditions. Results are expressed number of activated parietal cells as a percentage of total parietal cells counted \pm SE of four mice. $(P<0.02)$. (e) No change in HB-EGF protein expression. Western blot analysis of stomach protein $(50 \mu \mathrm{g}$ total protein per lane) shows no difference in expression of HB-EGF protein in TFF2-deficient (-/-) compared with wild-type mice $(+/+)$. Purified human HB-EGF was used as a positive control (not shown). M, size marker; MW, molecular weight.

ference that was significantly different $(P<0.02)$. The correlation between acid output and parietal cell activation suggests that increased parietal cell activation is the primary cause of the increased acid output in TFF2-deficient mice as opposed to a decrease in luminal buffering.

The increased basal acid secretion would be expected to lead to reduced gastrin levels. In fact, serum gastrin levels measured by RIA were below the limits of detection in TFF2-deficient mice compared with wild-type mice $(<10 \pm 0 \mathrm{pmol} / \mathrm{l}$ vs. $54 \pm 21 \mathrm{pmol} / \mathrm{l}, P<0.05)$.

Gastric mucosal expression of the two major epidermal growth factor receptor (EGF-R) ligands in the gastric mucosa, HB-EGF and TGF- $\alpha$, was measured. Neither HB-EGF (Figure 4e) or TGF- $\alpha(20.06 \pm 0.97 \mathrm{pg}$ TGF- $\alpha / \mathrm{mg}$ tissue vs. $20.47 \pm 2.83$ pg TGF- $\alpha / \mathrm{mg}$ tissue) were decreased in the gastric mucosa of TFF2-deficient animals compared with wild-type mice.

Increased susceptibility to NSAID-induced ulcer in TFF2-deficient mice. No gastric, duodenal, or small intestinal ulceration was identified in unchallenged TFF2-deficient mice. Mice in general appear to be somewhat resistant to peptic ulcer disease. However, a number of models of gastric ulceration have been developed, including the administration to rodents of NSAIDs such as indomethacin. The ulcers seen in mice after NSAID injury are typically linear, extending from the fundus to the antrum, and are mildly hemorrhagic. No evidence of blood clots or melena was seen. The extent and severity of indomethacin-induced gastric damage was dose dependent in both wild-type and TFF2-deficient mice. There was minimal gastric damage at $2.5 \mathrm{mg} / \mathrm{kg}$, but at $20-40 \mathrm{mg} / \mathrm{kg}$ there were extensive hemorrhagic mucosa lesions. No duodenal or small intestinal ulceration was 
a

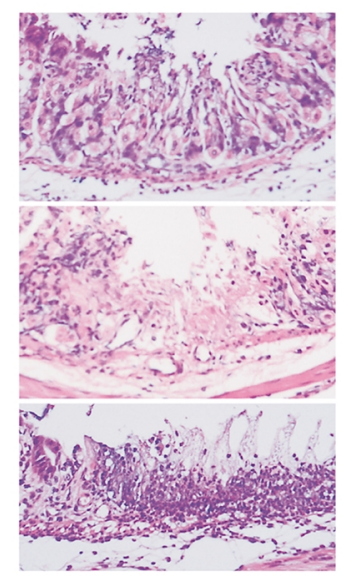

C

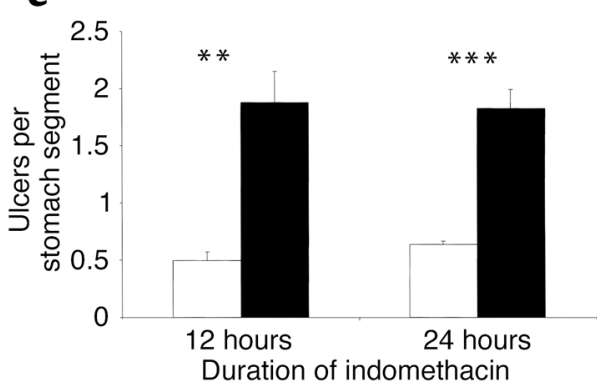

b

$\square$ Wild-type $\quad$ TFF2 deficient

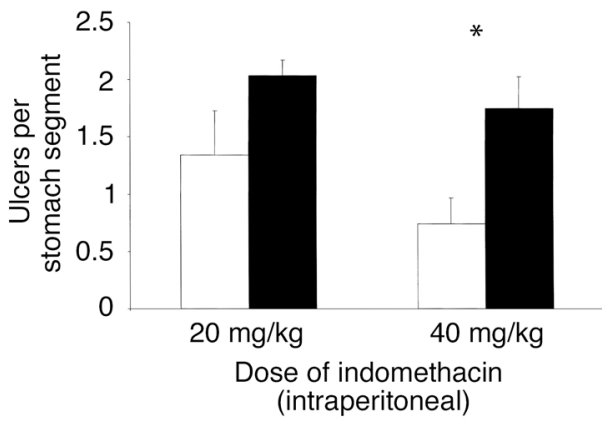

d

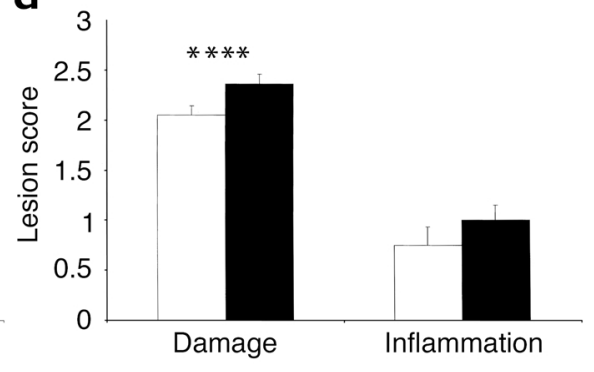

Figure 5

Increased indomethacin-induced gastric ulcers in TFF2-deficient mice. (a) Histological sections of indomethacin-induced ulceration in TFF2deficient mice. Superficial erosion with significant epithelial disruption and minimal inflammatory infiltrate (top). Deeper ulceration extending to the muscularis mucosae with moderate numbers of inflammatory cells (middle). Broad-based gastric ulceration with large numbers of inflammatory cells (bottom). (b) Dose response. Gastric mucosal lesions were assessed following administration of indomethacin (20 and $40 \mathrm{mg} / \mathrm{kg}$ ) for 12 hours and 1 hour following bethanechol $(2.5 \mathrm{mg} / \mathrm{kg})$. There was a significant difference $\left({ }^{*} P<0.03\right)$ with the $40 \mathrm{mg} / \mathrm{kg}$ dose, while there was not a clearly significant difference $(P<0.14)$ with the $20 \mathrm{mg} / \mathrm{kg}$ dose. (c) Time-dependent response with indomethacin 40 $\mathrm{mg} / \mathrm{kg}$. Gastric mucosal lesions were assessed 12 to 24 hours following administration of indomethacin ( $40 \mathrm{mg} / \mathrm{kg}$ ) and 1 hour following administration of bethanechol $(2.5 \mathrm{mg} / \mathrm{kg})$. Most gastric lesions were linear, thus data is expressed as mean of ulcers seen per horizontal stomach section (six horizontal sections per stomach). The differences at both 12 hours $(* * P<0.04)$ and 24 hours $\left({ }^{* *} P<0.02\right)$ were statistically significant. (d) Gastric indomethacin-induced ulcer damage and inflammation score. Ulcer score after administration of indomethacin $(20 \mathrm{mg} / \mathrm{kg})$ for 24 hours. Significant increase in ulcer damage score $(* * * P<0.03)$ seen in TFF2-deficient mice after administration of indomethacin $20 \mathrm{mg} / \mathrm{kg}$ for 24 hours compared with wild-type mice. No significant difference was seen in the inflammatory score between TFF2-deficient mice or wild-type mice.

noted in either TTF2-deficient mice or wild-type mice after administration of indomethacin. Ulceration was quantitated by histological examination of horizontal sections traversing the stomach. Gastric damage ranged from epithelial disruption with moderate inflammatory cell infiltrate (Figure 5a, top) to deeper ulceration with intense inflammatory cell infiltrate (Figure 5a, bottom). Importantly, there was a significantly greater number of ulcers in TFF2-deficient mice 12 hours and 24 hours after administration of indomethacin $40 \mathrm{mg} / \mathrm{kg}$ when compared with wild-type mice (Figure 5, b and c). Although there were an increased number of ulcers in TFF2-deficient mice after administration of indomethacin $20 \mathrm{mg} / \mathrm{kg}$ for 12 hours and 24 hours, this difference did not reach statistical significance. Howev$\mathrm{er}$, the effect of $20 \mathrm{mg} / \mathrm{kg}$ indomethacin was analyzed in greater depth using a previously validated ulcer scoring system that assessed both depth of ulcer in-jury and degree of associated inflammation. TFF2-deficient and wild-type mice administered indomethacin $(20 \mathrm{mg} / \mathrm{kg})$ were assessed using this scoring system at both 12 and 24 hours. Although no significant difference was seen in either the damage score or inflammation score at 12 hours (data not shown), there was a significant increase in the damage score $(2.36 \pm 0.1$ vs. $2.05 \pm 0.09, P<0.003)$ in TFF2-deficient mice compared with wild-type mice seen at 24 hours (Figure $5 \mathrm{~d}$ ). This increase in the damage score in the TFF2-deficient mice was accounted for by the presence of several large broad-based ulcers (Figure $5 \mathrm{a}$, bottom), which were seen only in the TFF2-deficient mice. Thus, absence of TFF2 leads to a greater number of NSAID-induced ulcers, especially at higher doses (40 $\mathrm{mg} / \mathrm{kg}$ ) of indomethacin administration and (with the $20 \mathrm{mg} / \mathrm{kg}$ dose) at later time points (24 hours).

\section{Discussion}

In this study, we have clarified the physiological roles of TFF2 in the gastric mucosa through the generation of 
TFF2-deficient mice by targeted gene disruption. Results from these mice confirm an important cytoprotective and restitutive role for TFF2. The gastric mucosal thickness of these mice was reduced compared with wild-type mice. Challenge of TFF2-deficient mice with indomethacin resulted in significantly increased gastric ulceration compared with wild-type mice. These findings in TFF2-deficient animals support previous reports that showed that treatment of rats with recombinant TFF2, given by either oral gavage or intravenous administration, resulted in significant protection against both NSAID- and ethanol-induced gastric ulceration $(27,28)$.

TFF2-deficient mice showed at least twofold increased level of basal and stimulated acid output, which could be demonstrated through both direct titration of gastric acid, as well as assessment of numbers of activated parietal cells by transmission electronic microscopy. Such findings are consistent with previous reports demonstrating suppression of acid secretion after administration of TFF 2 to rats $(14,25)$, although there is also experimental evidence to suggest that relatively high concentrations of TFF 2 have no effect on basal or pentagastrin-stimulated acid secretion $(41,42)$. However, a role for TFF2 in physiological regulation of gastric acid secretion had not been reported previously and it is possible that the negative results from these earlier studies may be related to the pharmacologic preparations of TFF2, the mode of delivery, or other limitations of the model systems. In our analyses, the increased basal acid and stimulated acid secretion, along with the noted increase in activated parietal cells and decreased gastrin levels, are all strongly suggestive of a role of TFF 2 in acid suppression. TFF2-deficient mice showed a nearly twofold increase in the numbers of activated parietal cells and in the amount of $\mathrm{H}^{+}$secreted. The increase in gastric acid secretion seen in TFF2-deficient mice might be expected to predispose them to ulcer disease, and while no ulcers were observed in unstressed animals, an increased susceptibility to NSAID-induced gastric ulceration was observed in TFF2deficient mice. The pathophysiologic significance of this rise in acid output could be further examined in TFF2deficient mice challenged by Helicobacter infection, and this is a priority for further study.

The ability of TFF 2 to inhibit gastric acid secretion would be consistent with its role in mucosal healing and repair. Thus a breach in the gastric mucosa would lead to rapid upregulation of TFF 2 expression and possibly a reduction in gastric acid production, partly protecting damaged mucosa from acid injury and contributing to healing. Previous studies demonstrating an increase in TFF2 expression after gastric injury have not assessed gastric acid output in this setting (19).

In addition to its role in suppression of gastric acid, studies in TFF2-deficient mice demonstrated a possible role for TFF2 in the modulation of glandular proliferation. A possible role for TFF2 in gastric epithelial proliferation has remained controversial. An effect of TFF2 on proliferation was first suggested by Hoosein et al., who showed that a highly purified preparation of porcine
TFF2 was able to stimulate $\left[{ }^{3} \mathrm{H}\right]$ thymidine-incorporation of HCT 116 colon carcinoma cells $(24,43)$. However, studies by Dignass et al. and Playford et al. have suggested no effect of TTF2 on proliferation, again using intestine cell lines $(44,45)$ In our study, TFF2-deficient mice showed a $35 \%$ reduction in the fundic proliferation rate compared with wild-type mice. This decreased proliferation rate most likely accounted for the decreased mucosal thickness. Although there was a significant decrease in both the pit region height and the glandular height in the TFF2-deficient mice, there was no difference in the total number of parietal cells per gland to account for the decrease in gland height, and the number of chief cells showed only a modest decrease that did not reach statistical significance. There is a modest increase in endocrine cells in the TFF2, the cause and significance of which is unclear. It is possible that the decreased mucous neck cells may contribute to the thinner mucosa, although this may be offset by the increase in endocrine cells. The decrease in mucous neck cells is not unexpected because this is the primary source of TFF2 in the gastric mucosa. This suggests a role for TFF2 in the autoregulation of the mucous neck cell kinetics. It is also possible that alterations in cell size may account for why the mucosa is thinner in TFF2-deficient mice, although this was not specifically analyzed.

It is also possible the hypogastrinemia seen in the TFF2-deficient mice could contribute to the thinner mucosa and reduced labeling index. However, it should be noted that our published analysis of the gastrin knockout mouse shows no similar decrease in the gastric-labeling index, suggesting that reduced gastrin is unlikely to account on its own for the decrease in mucosal proliferation (35).

The effects of TFF 2 on both proliferation and acid inhibition might be mediated through binding to a specific receptor, although this question is still unresolved. Several groups have described saturable binding activity by porcine TFF 2 within isolated rat intestinal membranes $(46,47)$. In addition, Poulsen et al. have shown the presence of TFF2-binding sites in the mucosal neck cells of the rat stomach (30). More recently, a TFF2binding protein has been purified and characterized by Thim et al. (29) that is identical to a previously cloned gene product called CRP-ductin (also named MUCLIN), which is known to be expressed in the intestinal crypts. However, it remains to be determined whether this or other previously characterized binding proteins actually can function as TFF2 receptors.

The TFF2-deficient mice were more susceptible to NSAID-induced gastric ulceration, which is consistent with previous studies, suggesting a gastric cytoprotective effect of TFF $2(24,25,44,45)$. The healing of gastric ulcers is generally a dynamic process that requires both proliferative and migratory responses. Our results suggest that the decrease in proliferation may be a significant factor in the greater susceptibility of the TFF2deficient mice to gastric ulceration. The greater damage score recorded in TFF2-deficient mice at 24 hours 
compared with 12 hours suggests that TFF 2 may have a greater role in later mucosal restitution than in initial prevention against ulcer formation. A decrease in proliferation would be one such possible mechanism affecting restitution process.

Several groups have demonstrated previously the induction of EGF-R and MAP kinases (ERK1 and ERK2) in the healing gut mucosa (48-50), and inhibition of EGF-R with tyrphostin A46 inhibits ulcer healing. However, no single EGF-R ligand has been demonstrated to be critical for gastrointestinal healing. We have shown previously that stimulation of gastric cell lines with TFF2 leads to phosphorylation of EGF-R and activation of MAP kinases (51) and that it is MAP-kinase activation that is mainly responsible for the trefoil-mediated initiation of healing (12). Trefoils are immediate-early genes (51), and the increase in TFF2 gene expression after injury is rapid (19). These data combined with the present study suggest that TFF2 may integrate the early repair program within the gastric mucosa. In addition, EGF-R signaling has also been shown to inhibit parietal cell activity and secretion (52) and thus would be a reasonable mechanism to postulate for its acid inhibitory effects, as well. However, our results show that the two major ligands of EGF-R (HB-EGF and TGF- $\alpha$ ) are not decreased in the gastric mucosa of TFF2-deficient animals compared with wild-type mice. Thus, decreased levels of EGF-R ligands are unlikely to account directly for the phenotype described. TFF2 might affect cleavage or autocrine release of HB-EGF/TGF- $\alpha$ without any change in tissue levels of these growth factors. Further studies will be needed to determine the role, if any, for EGF-R signaling in the physiologic action of TFF2.

A role for TFF2 in gastric proliferation has been suspected from earlier studies demonstrating a close relationship between TFF 2 and the proliferative zone of the stomach in both human and models. While TFF2 expression has been consistently localized to the normal proliferative zone of the gastric mucosa in both human and rodent models, a possible role in the regulation of this proliferative compartment has not been proven. However, expression of TFF2 is consistently increased in association with the expansion of the proliferative zone during regenerative processes such as ulcer healing, and TFF2 expressions remains both temporally and spatially associated with proliferative markers (such as PCNA) under these conditions. Given the significant decrease in proliferation found in our TFF2deficient mice, it seems clear that TFF2 plays an important role, directly or indirectly, in regulating the proliferative compartment of the stomach. These findings are, in fact, opposite those reported in mice deficient in TFF1/pS2, which show an increased rate of proliferation (13); interestingly, recent genetic data have supported a role for TFF $1 / \mathrm{pS} 2$ as a tumor suppressor gene (53). It is unclear why two structurally similar proteins act differently on proliferation.

A role for TFF2 in stimulating proliferation is not without implications for more serious diseases of the

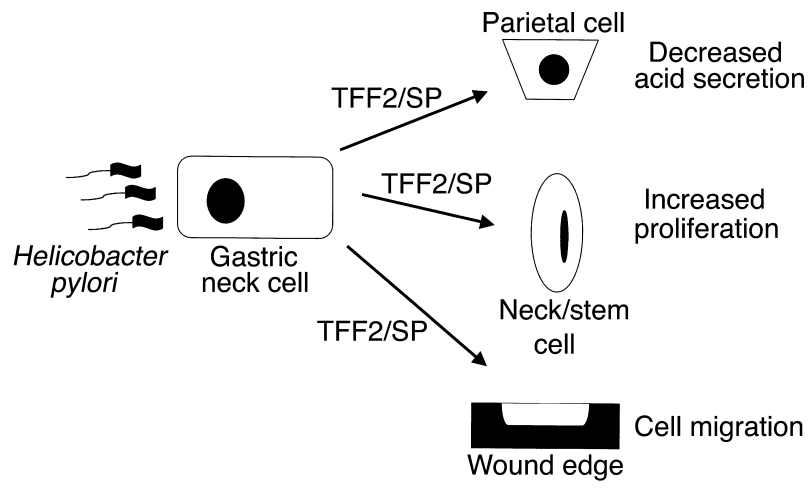

Figure 6

Role for TFF2/SP in gastric physiology and disease. In the setting of injury and/or chronic Helicobacter pylori infection, increased TFF2 expression and secretion may stimulate proliferation and inhibit acid secretion. This would promote wound healing, but also contribute directly to increased gastric cancer risk.

stomach such as gastric cancer. While short-term upregulation of TFF2 appears to be helpful in ulcer healing, prolonged upregulation may in fact contribute to neoplastic progression. Increases in TFF2 expression have been observed in preneoplastic lesions of the stomach. A metaplastic cell lineage expressing TFF2 (termed SPEM) is consistently upregulated in a variety of mouse models that show both preneoplastic and neoplastic changes in the stomach, particularly in association with Helicobacter infection $(22,23,54)$. In addition, this SPEM-lineage is clearly present in patients with fundic Helicobacter pylori-associated gastritis and is strongly associated with the presence of both dysplasia and gastric adenocarcinoma (21). In the setting of chronic Helicobacter infection, increased TFF2 expression and secretion could contribute directly to gastric cancer risk not only through stimulation of proliferation, but also through inhibition of acid secretion (Figure 6). Further studies will be required to define the role of TFF2 in $H$. pylori-associated chronic gastritis and gastric cancer.

\section{Acknowledgments}

The authors express sincere thanks to Ian Rosenberg, Natalie Sinclair, and Dana Frederick for their assistance with Western and Northern blot analysis; Jane Carlson for her assistance with the gastric acid secretion model; Paul Beck for advice on the mouse NSAID model; Sus Itoh for his skill in electron microscopy; Graham J. Dockray and Andrea Varro for help in the RIA measurements of plasma amidated gastrin in mice; Robert Coffey and Galina Bogatcheva for performing the RIA measurements of TGF- $\alpha$ in gastric tissue; and Michael Höcker for his assistance in cloning of the TFF2 gene. Oligonucleotides and knockout mice were developed with support from the Center for the Study of Inflammatory Bowel Disease. The work was supported by grants from the NIH to Timothy C. Wang (RO1 DK-52778, RO1 DK-48077, and RO1 DK-58889-01) and to Daniel K. Podolsky (DK-41577 and DK-43351). 
1. Lefebvre, O., et al. 1993. The mouse one P-domain (pS2) and two $\mathrm{P}$-domain $(\mathrm{mSP})$ genes exhibit distinct patterns of expression. J. Cell Biol. 122:191-198.

2. Jeffrey, G.P., Oates, P.S., Wang, T.C., Babyatsky, M.W., and Brand, S.J. 1994. Spasmolytic polypeptide: a trefoil peptide secreted by rat gastric mucous cells. Gastroenterology. 106:336-345.

3. Tomasetto, C., et al. 1990. hSP, the domain-duplicated homolog of pS2 protein, is co-expressed with pS2 in stomach but not in breast carcinoma. EMBO. J. 9:407-414

4. Suemori, S., Lynch-Devaney, K., and Podolsky, D.K. 1991. Identification and characterization of rat intestinal trefoil factor: tissue- and cell-specific member of the trefoil protein family. Proc. Natl. Acad. Sci. USA. 88:11017-11021.

5. Podolsky, D.K., et al. 1993. Identification of human intestinal trefoil factor. Goblet cell-specific expression of a peptide targeted for apical secretion [erratum 1993, 268:12230]. J. Biol. Chem. 268:6694-6702.

6. Mashimo, H., Podolsky, D.K., and Fishman, M.C. 1995. Structure and expression of murine intestinal trefoil factor: high evolutionary conservation and postnatal expression. Biochem. Biophys. Res. Commun. 210:31-37.

7. Mashimo, H., Wu, D.C., Podolsky, D.K., and Fishman, M.C. 1996. Impaired defense of intestinal mucosa in mice lacking intestinal trefoil factor. Science. 274:262-265.

8. Nusrat, A., Delp, C., and Madara, J.L. 1992. Intestinal epithelial restitution. Characterization of a cell culture model and mapping of cytoskeletal elements in migrating cells. J. Clin. Invest. 89:1501-1511.

9. Santos, M.F., et al. 1997. Rho proteins play a critical role in cell migration during the early phase of mucosal restitution. J. Clin. Invest. 100:216-225.

10. Dieckgraefe, B.K., Stenson, W.F., and Alpers, D.H. 1996. Gastrointestinal epithelial response to injury. Curr. Opin. Gastroenterol. 12:109-114.

11. Dignass, A., Lynch-Devaney, K., Kindon, H., Thim, L., and Podolsky, D.K. 1994. Trefoil peptides promote epithelial migration through a transforming growth factor beta-independent pathway. J. Clin. Invest. 94:376-383.

12. Kinoshita, K., Taupin, D.R., Itoh, H., and Podolsky, D.K. 2000. Distinct pathways of cell migration and antiapoptotic response to epithelial injury: structure-function analysis of human intestinal trefoil factor. Mol. Cell Biol. 20:4680-4690.

13. Lefebvre, O., et al. 1996. Gastric mucosa abnormalities and tumorigenesis in mice lacking the pS2 trefoil protein. Science. 274:259-262.

14. Jorgensen, K.D., Diamant, B., Jorgensen, K.H., and Thim, L. 1982. Pancreatic spasmolytic polypeptide (PSP). III. Pharmacology of a new porcine pancreatic polypeptide with spasmolytic and gastric acid secretion inhibitory effects. Regul. Pept. 3:231-243.

15. Hanby, A.M., et al. 1993. Spasmolytic polypeptide is a major antral peptide: distribution of the trefoil peptides human spasmolytic polypeptide and pS2 in the stomach. Gastroenterology. 105:1110-1116.

16. Hoffmann, W., and Hauser, F. 1993. The P-domain or trefoil motif: a role in renewal and pathology of mucous epithelia? Trends Biochem. Sci. 18:239-243.

17. Rio, M.C., et al. 1991. Induction of pS2 and hSP genes as markers of mucosal ulceration of the digestive tract. Gastroenterology. 100:375-379.

18. Wright, N.A., et al. 1993. Trefoil peptide gene expression in gastrointestinal epithelial cells in inflammatory bowel disease. Gastroenterology. 104:12-20.

19. Alison, M.R., et al. 1995. Experimental ulceration leads to sequential expression of spasmolytic polypeptide, intestinal trefoil factor, epidermal growth factor and transforming growth factor alpha mRNAs in rat stomach. J. Pathol. 175:405-414.

20. Wright, N.A., et al. 1990. Epidermal growth factor (EGF/URO) induces expression of regulatory peptides in damaged gastrointestinal tissues. J. Pathol. 162:279-284.

21. Schmidt, P.H., et al. 1999. Identification of a metaplastic cell lineage associated with human gastric adenocarcinoma. Lab. Invest. 79:639-646.

22. Wang, T.C., et al. 1998. Mice lacking secretory phospholipase A2 show altered apoptosis and differentiation with Helicobacter felis infection. Gastroenterology. 114:675-689.

23. Wang, T.C., et al. 2000. Synergistic interaction between hypergastrinemia and Helicobacter infection in a mouse model of gastric cancer. Gastroenterology. 118:36-47.

24. Hoosein, N.M., Thim, L., Jorgensen, K.H., and Brattain, M.G. 1989. Growth stimulatory effect of pancreatic spasmolytic polypeptide on cultured colon and breast tumor cells. FEBS Lett. 247:303-306.

25. Konturek, P.C., et al. 1997. Role of spasmolytic polypeptide in healing of stress-induced gastric lesions in rats. Regul. Pept. 68:71-79.

26. Tanaka, S., Podolsky, D.K., Engel, E., Guth, P.H., and Kaunitz, J.D. 1997. Human spasmolytic polypeptide decreases proton permeation through gastric mucus in vivo and in vitro. Am. J. Physiol. 272:G1473-G1480.

27. Babyatsky, M.W., deBeaumont, M., Thim, L., and Podolsky, D.K. 1996.
Oral trefoil peptides protect against ethanol- and indomethacin-induced gastric injury in rats. Gastroenterology. 110:489-497.

28. McKenzie, C., Thim, L., and Parsons, M.E. 2000. Topical and intravenous administration of trefoil factors protect the gastric mucosa from ethanol-induced injury in the rat. Aliment. Pharmacol. Ther. 14:1033-1040.

29. Thim, L., and Mortz, E. 2000. Isolation and characterization of putative trefoil peptide receptors. Regul. Pept. 90:61-68.

30. Poulsen, S.S., Thulesen, J., Nexo, E., and Thim, L. 1998. Distribution and metabolism of intravenously administered trefoil factor 2 /porcine spasmolytic polypeptide in the rat. Gut. 43:240-247.

31. Mashimo, H., Podolsky, D.K., and Fishman, M.C. 1995. Structure and expression of murine intestinal trefoil factor: high evolutionary conservation and postnatal expression. Biochem. Biophys. Res. Commun. 210:31-37.

32. Sambrook, J.F., Fritsch, E.F., and Maniatis, T. 1989. Molecular cloning: a laboratory manual. 2nd edition. Cold Spring Harbor Laboratory Press. Plainview, New York, USA.

33. Tybulewicz, V.L., Crawford, C.E., Jackson, P.K., Bronson, R.T., and Mulligan, R.C. 1991. Neonatal lethality and lymphopenia in mice with a homozygous disruption of the c-abl proto-oncogene. Cell. 65:1153-1163.

34. Chen, D., et al. 2000. Glycine-extended gastrin synergizes with gastrin 17 to stimulate acid secretion in gastrin-deficient mice. Gastroenterology. 119:756-765

35. Koh, T.J., et al. 1997. Gastrin deficiency results in altered gastric differentiation and decreased colonic proliferation in mice. Gastroenterology. 113:1015-1025

36. Wang, T.C., et al. 1996. Processing and proliferative effects of human progastrin in transgenic mice. J. Clin. Invest. 98:1918-1929.

37. Langhans, N., et al. 1997. Abnormal gastric histology and decreased acid production in cholecystokinin-B/gastrin receptor-deficient mice. Gastroenterology. 112:280-286.

38. Varro, A., Voronina, S., and Dockray, G.J. 1995. Pathways of processing of the gastrin precursor in rat antral mucosa. J. Clin. Invest. 95:1642-1649.

39. Beck, P.L., et al. 2000. Mechanisms of NSAID-induced gastrointestinal injury defined using mutant mice. Gastroenterology. 119:699-705.

40. Sands, B.E., and Podolsky, D.K. 1996. The trefoil peptide family. Annu Rev. Physiol. 58:253-273.

41. McKenzie, C., et al. 1997. Pancreatic spasmolytic polypeptide protects the gastric mucosa but does not inhibit acid secretion or motility. Am.J. Physiol. 273:G112-G117.

42. Playford, R.J., et al. 1995. Human spasmolytic polypeptide is a cytoprotective agent that stimulates cell migration. Gastroenterology. 108:108-116.

43. Otto, W.R., et al. 1996. Effects of pancreatic spasmolytic polypeptide (PSP) on epithelial cell function. Eur. J. Biochem. 235:64-72.

44. Dignass, A., Lynch-Devaney, K., Kindon, H., Thim, L., and Podolsky, D.K 1994. Trefoil peptides promote epithelial migration through a transforming growth factor beta-independent pathway. J. Clin. Invest. 94:376-383.

45. Playford, R.J., et al. 1995. Human spasmolytic polypeptide is a cytoprotective agent that stimulates cell migration. Gastroenterology. 108:108-116.

46. Frandsen, E.K., Jorgensen, K.H., and Thim, L. 1986. Receptor binding of pancreatic spasmolytic polypeptide (PSP) in rat intestinal mucosal cell membranes inhibits the adenylate cyclase activity. Regul. Pept. 16:291-297.

47. Frandsen, E.K. 1988. Receptor binding of pancreatic spasmolytic polypeptide in intestinal mucosal cells and membranes. Regul. Pept. 20:45-52

48. Hansson, H.A., Hong, L., Helander, H.F. 1990. Changes in gastric EGF, EGF receptors, and acidity during healing of gastric ulcer in the rat. Acta. Physiol. Scand. 138:241-242.

49. Tarnawski, A., Stachura, J., Durbin, T., Sarfeh, I.J., and Gergely, H. 1992. Increased expression of epidermal growth factor receptor during gastric ulcer healing in rats. Gastroenterology. 102:695-698.

50. Pai, R., Ohta, M., Itani, R.M., Sarfeh, I.J., and Tarnawski, A.S. 1998. Induction of mitogen-activated protein kinase signal transduction pathway during gastric ulcer healing in rats. Gastroenterology. 114:706-713.

51. Taupin, D., et al. 1999. The trefoil gene family are coordinately expressed immediate-early genes: EGF receptor- and MAP kinase-dependent interregulation. J. Clin. Invest. 103:R31-R38.

52. Joshi, V., Ray, G.S., and Goldenring, J.R. 1997. Inhibition of parietal cell acid secretion is mediated by the classical epidermal growth factor receptor. Dig. Dis. Sci. 42:1194-1198.

53. Park, W.S., et al. 2000. Somatic mutations of the trefoil factor family 1 gene in gastric cancer. Gastroenterology. 119:691-698.

54. Goldenring, J.R., et al. 1996. Expression of trefoil peptides in the gastric mucosa of transgenic mice overexpressing transforming growth factoralpha. Growth Factors. 13:111-119. 